\section{Social mechanisms to facilitate the agroecological transition of agri-food systems}

\author{
Review by Philippe Jeanneaux * \\ VetAgro Sup, Joint Research Unit Territoires
}

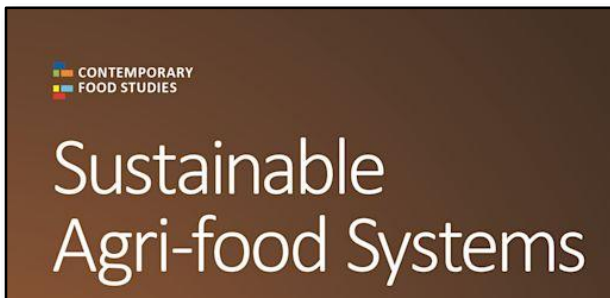

Case Studies in Transitions Towards Sustainability from France and Brazil Claire Lamine

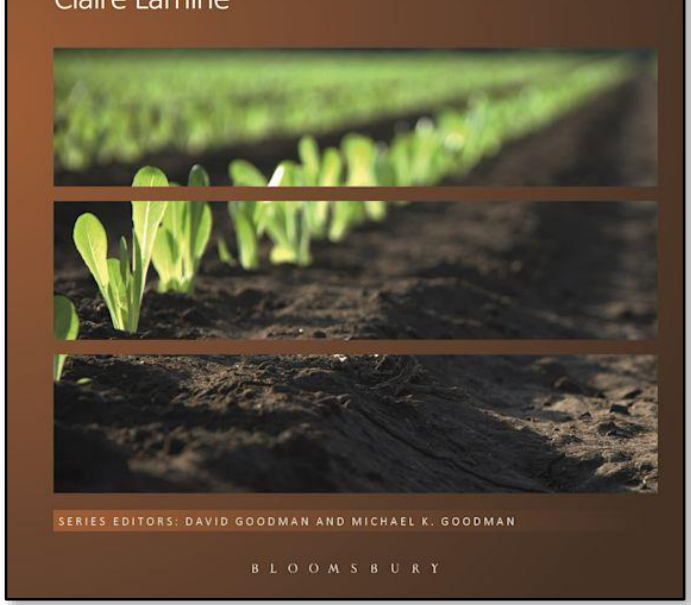

Review of: Sustainable Agri-Food Systems: Case Studies in Transitions Towards Sustainability From France and Brazil, by Claire Lamine. (2020). Bloomsbury. Available as hardcover, paperback, and ebook (PDF, Epub, and Mobi); 224 pages. Publisher's website: https://www.bloomsbury.com/us/sustainable-agri-foodsystems-9781350101128/

Citation: Jeanneaux, P. (2022). Social mechanisms to facilitate the agroecological transition of agri-food systems [Book review]. Journal of Agriculture, Food Systems, and Community Development, 11(2), 303-305. https://doi. re/10.5304/1atscd.2022.112.009

Copyright (C) 2022 by the Author. Published by the Lyson Center for Civic Agriculture and Food Systems. Open access under CC-BY license.

$\mathrm{T}$ his book is built on 15 years of scholarship in sociology, which gave Claire Lamine the opportunity to get her accreditation to supervise Ph.D. students. For an experienced academic in France, this kind of manuscript is like writing a second doctoral dissertation. That explains why this 224-page book is dense and mixes a strong

\footnotetext{
* Philippe Jeanneaux is a professor of economics at VetAgro Sup, Joint Research Unit Territoires (in Lempdes, France), where he teaches farm management and agricultural economics. His research includes farm performance, agri-food chain dynamics and organization. He can be contacted at philippe.jeanneaux@vetagro-sup.fr
}

theoretical basis and original empirical research. The book relates in-depth case studies from France and Brazil at different scales and provides a critical survey of social science approaches to sustainability transitions in agri-food systems. Lamine presents an original sociological approach to address the diverse pathways of transition encountered across multiple levels, from the farm through farmers' networks and food chains, to the territorial scale of regions and states. She presents experiences carried out by stakeholders involved in agri-food systems to explore new possible connections between agriculture, food, environment, and health, while also considering social equity issues. 
I recommend this book because by combining theoretical and conceptual elements borrowed from different sociological schools, Lamine outlines in seven chapters a comprehensive approach for understanding the complex issue of agri-food system transitions toward sustainability. Lamine's work adopts a comparative perspective to explore the transition of agroecology and the specific modes of governance involved in France and Brazil— two countries that have a strong agriculture and pioneer the implementation of ecological approaches in agriculture, but that differ both in vision and context. Although Lamine is a sociologist, her book addresses agri-food systems transitions through the study of geography, sociology, politics, farming, and food systems. I would especially recommend reading the introduction, which gives a very clear understanding of the content of this book.

In the first chapter, Lamine provides an overview of the theoretical approaches that have been used in the social sciences to study transitions toward sustainability in agri-food systems. Three main approaches are presented: First, the North American theory of food regimes (Friedmann \& McMichael, 1989), which is rooted in the Marxist political economy, adopts a critical stance on power relations within agri-food systems, and analyzes the changes produced over long periods of time and on macro scales. Secondly, Lamine focuses on the theories of transitions and, based on the multi level perspective approach (Geels, 2010), takes a macroscopic view of transition processes, considering that these processes are the result of interactions between socio-technical context and regime, as well as niches of innovation that develop and influence the dominant system. Thirdly, Lamine presents the French pragmatic sociology approach to highlight the ordinary changes of actors and the cognitive and moral aspects of their arguments in ordinary situations of coordination and conflict. Lamine thus puts into perspective different concepts of these three approaches to build an original approach to analyze and understand the transition of agri-food systems toward greater sustainability.

In the book, the concept of "agri-food system" highlights the interactions between agri-food dynamics and practices, including the production, processing, distribution, and consumption of food. In particular, it is defined as a system of actors and institutions with different visions and objectives, where conflicts and bargaining power are common but which are embedded in interdependent dynamics. Lamine can then argue that debates, controversies, and conflicts are necessary to unravel the complexity of argumentative processes and understand why and how some visions and models become more influential and dominant while others are marginalized. This theoretical framework could then be used to analyze several transition situations and not only for agri-food systems. This is one of the major outcomes of this research program.

Lamine builds on and strengthens this framework by articulating three methodological approaches: systemic, dynamic, and pragmatist. The first principle (systemic) aims to take into account interdependencies that exist between the different components of the agri-food system: the actors, institutions, rules, and instruments involved in the production, processing, distribution, and consumption of food. The second principle (dynamic) recommends studying the transformation process that, over time, redefines (or not) the interdependencies that hinder or encourage the processes of ecologization. The third principle (pragmatist) postulates that agri-food systems are systems of actors and institutions guided by different ideas, visions, and goals that may be confronted by controversies and conflicts.

The following six chapters illustrate the application of this approach to several empirical cases in France and Brazil, at different scales of analysis. Chapter 2 studies ecologization processes at the farm level. It shows that it is difficult for a farmer - faced with greater uncertainty-to change, because the ecological transition has effects on their values and changes both their identity and their conception of their work. But this process is also an opportunity for farmers to learn more about autonomy and resilience as crucial components of their contribution to the sustainable development of their community. Chapter 3 discusses the role of farm extension services and the collective dynamics around farmers that are critical to facilitate ecological transition. Chapter 4 illustrates socio-technical 
interlocks or triggering events that play a role in the ecological transition at the scale of the agri-food chain by considering the diversity of linkages and stakeholders. Chapter 5 adopts a territorial scale to argue that the territory is the relevant scale for analyzing transitions in agri-food systems because it is the scale where ecological, social, economic, and health processes interact directly. It is also because this scale makes it easier to bring together academic research and the actors at the heart of transformative action of agri-food systems.

The last two chapters, 6 and 7, deal with the political building of agroecological projects in France and Brazil over the last decade. Lamine draws lessons from different experiences that could be taken into account in future agro-ecology policies at the national level to accelerate the reconnection between agriculture, environment, food, and health within sustainable agri-food systems. Thus, Lamine shows that sustainable agri-food systems and social justice are completely linked because food (nutritional security) is the outcome of the convergence of social movements (actions, claims, and conflicts). There is no food security without social justice.

This book makes a valuable contribution to the reflection on social science analytical frameworks that apprehend the transition toward the sustainability of agri-food systems, by considering this transition's complexity and identifying the mechanisms that facilitate or hinder it. I recommend this book to undergraduate classes and graduate seminars, academic libraries, and individuals interested in social mechanisms to facilitate the agroecological transition.

\section{References}

Friedmann, H., \& McMichael, P. (1989). Agriculture and the state system: The rise and fall of national agricultures, 1870 to the present. Sociologia Ruralis, 29(2), 93-117. https://doi.org/10.1111/j.1467-9523.1989.tb00360.x

Geels, F. W. (2010). Ontologies, socio-technical transitions (to sustainability), and the multi-level perspective. Research Policy, 39(4), 495-510. https://doi.org/10.1016/j.respol.2010.01.022 